\title{
Optimizing the nutrient feeding strategy for PHA production by a novel strain of Enterobacter sp.
}

\author{
V. Vinish $\cdot$ S. H. Sangeetha $\cdot$ J. Aravind $\cdot$ \\ P. Kanmani $\cdot$ T. Sathiskumar
}

Received: 8 August 2014/Revised: 10 January 2015/ Accepted: 17 February 2015/Published online: 4 March 2015

(C) Islamic Azad University (IAU) 2015

\begin{abstract}
The influence of nutrient limitation on polyhydroxyalkanoate (PHA) accumulation was studied using a novel PHA-producing strain of Enterobacter sp. The effect of N/C ratio on growth and accumulation of PHA was studied by varying the ratio from 0.02 to 0.1 . Biomass concentration, dry cell weight, protein content and the amount of PHA accumulated were estimated for each N/C ratio. It was found that the increase in N/C ratio resulted in increase in culture concentration up to $3.25 \mathrm{~g} / \mathrm{l}$ of dry cell weight. Polyhydroxyalkanoate concentration was found to be maximum at $\mathrm{N} / \mathrm{C}$ ratio of $0.04(67.8 \mu \mathrm{g} / \mathrm{ml})$, and further increase in N/C ratio resulted in lesser amount of PHA. Analytical procedures such as FTIR and NMR were done to validate the obtained PHA biopolymer.
\end{abstract}

Keywords PHA - Novel strain - Enterobacter sp. . Nutrient limitation $\cdot$ N/C ratio $\cdot$ FTIR $\cdot$ NMR

\section{Introduction}

About 180 million tons of plastics are known to be produced annually worldwide and are accumulated in landfills causing lethal damage to our ecosystem (Thompson et al. 2009). The current research is focused on natural ecofriendly biopolymers and bioplastic production. Biodegradable polymers such as polyhydroxyalkanoate (PHA) (Heimersson et al. 2014), polylactates (PLA)

V. Vinish $\cdot$ S. H. Sangeetha $\cdot$ J. Aravind $(\bowtie) \cdot$ P. Kanmani · T. Sathiskumar

Department of Biotechnology, Kumaraguru College of

Technology, Coimbatore 641049, India

e-mail: dr.j.aravind@gmail.com possess physical and mechanical properties similar to that of synthetic plastics (Poirier et al. 1995; Laycock et al. 2014) and are widely used in various fields such as agriculture, medicine and polymer blend manufacturing (Philip et al. 2007). They find specific applications such as blended packaging materials, sutures, cardiovascular stents and scaffold (Scholz and Gross 2000). PHAs are polyesters accumulated as intracellular products by microorganisms under nutrient-limiting condition of nitrogen, phosphorous or potassium when excess carbon is available (Ostle and Holt 1982). It was found that Ralstonia eutropha, a facultative autotroph, accumulated about $80 \%$ of its dry cell weight as PHA from simple carbon sources such as glucose, fructose and acetic acid and was widely exploited for large-scale production (Anderson and Dawes 1990). Various other genera including Acinetobacter, Sphingobacterium, Yokenella, Brochotrix, Lactobacillus, Streptococcus and Lactococcus (Dalal et al. 2010 and Yuksekdag et al. 2003) have also been reported for PHA production. The large-scale production of PHA is limited because of its high raw material cost and low productivity (Ojumu et al. 2004). Hence, the current research work is focused on exploring new strains and using low-cost renewable substrates for the production process (Albuquerque et al. 2007; Reddy et al. 2013). As stated by Ostle and Holt (1982), PHA accumulates under limitation of an essential nutrient in the medium. The influence of different degrees of carbon and nitrogen limitation on acetate-fed medium was studied in a sequencing batch reactor (SBR), and higher PHA content was found at nitrogen-limited conditions. Kinetics of biopolymer accumulation in $\mathrm{Al}$ caligenes eutrophus was studied by Raje and Srivasta (1998) under various $\mathrm{C} / \mathrm{N}$ ratios. Maximum production was found at $0.09 \mathrm{C} / \mathrm{N}$ ratio, resulting in a mathematical model providing a new feed strategy for production process. The 
present study deals with the behavior of PHA accumulation in a novel strain of Enterobacter sp., under varying nutrient feeding strategies.

\section{Materials and methods}

Culture and media composition

A novel strain for PHA production was isolated from soil (KCT campus, Coimbatore, India) and was identified by $16 \mathrm{~S}$ rRNA gene sequencing. The culture was preserved in $20 \%$ glycerol stock and was revived in nutrient medium and further used. Medium composition was as follows: glucose $(10 \mathrm{~g} / \mathrm{l})$, sodium chloride $(5 \mathrm{~g} / \mathrm{l})$, dipotassium hydrogen phosphate $(5 \mathrm{~g} / \mathrm{l})$, magnesium sulfate $(1 \mathrm{~g} / \mathrm{l})$ and ammonium chloride $(0.2-1 \mathrm{~g} / \mathrm{l})$.

\section{Experimental procedure}

The work was carried out in shake flask conditions by varying N/C ratio with glucose as a carbon source and ammonium chloride as nitrogen source. The culture was grown for $48 \mathrm{~h}$ at room temperature in minimal media $(\mathrm{pH}$ of the media was initially adjusted to 7.5) containing varying N/C ratios from 0.02 to 0.1 and was checked for biomass concentration, dry cell weight, protein content, glucose content and PHA concentration for every $2 \mathrm{~h}$.

Biomass concentration and dry cell weight estimation

Biomass estimation was done by measuring OD at $660 \mathrm{~nm}$ using visible spectrophotometer. Later, the culture was centrifuged and the obtained cell pellet was dried in a preweighed aluminum foil for dry cell weight estimation.

\section{Glucose and protein concentration}

The amounts of residual glucose and protein in media were estimated by 3, 5-dinitrosalicylic acid and Lowry's method, respectively. The concentrations were found from the respective standard curves by measuring absorbance at 540 and $600 \mathrm{~nm}$ using visible spectrophotometer.

\section{Quantification of PHA}

PHA concentration was determined using spectrophotometer by converting it into crotonic acid by heating with

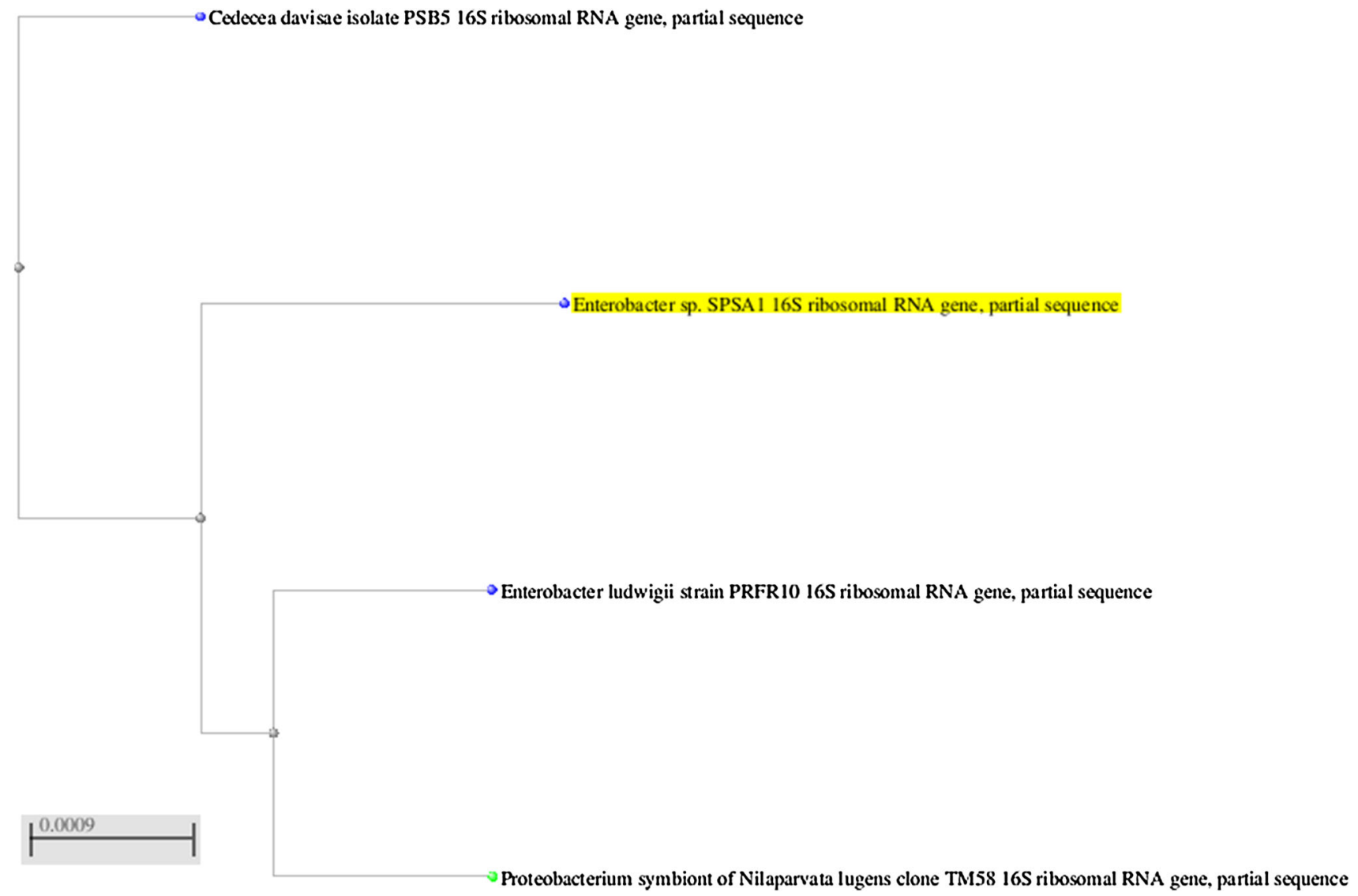

Fig. 1 Phylogenetic tree for novel strain of Enterobacter sp. 
sulfuric acid according to the procedure of Law and Slepecky (1969).

Characterization of PHA

FTIR

The obtained PHA granule was processed into $\mathrm{KBr}$ pellets, and infrared spectroscopy was recorded in the spectrum range $400-4000 \mathrm{~cm}^{-1}$. The spectrum obtained was compared to standard PHB.

$N M R$

Nuclear magnetic resonance can be used for structure determination of PHA. The samples were dissolved in deuterated chloroform and operated at $400 \mathrm{MHz}$ for $\mathrm{H}^{1}$. The chemical shifts were represented in ppm with respect to the signal in the spectrum and used for prediction of monomer composition of PHA (Sanchez et al. 2003).

\section{Molecular identification}

The bacterial isolate was identified using 16S rRNA gene sequence-based molecular technique. Single colony from freshly streaked agar plate was inoculated into nutrient broth. DNA was isolated and checked on agarose gel for purity and quantity. 16s rRNA gene primers $27 \mathrm{~F}\left(5^{\prime}-\right.$ AGAGTTTGATC(A/C)TGGCTCAG- $\left.3^{\prime}\right)$ and 1492R (5' ACGG(C/T)TACCTTGTTACGACTT- $3^{\prime}$ ) were used to amplify $\sim 1.4 \mathrm{~Kb}$ gene from the isolated genomic DNA (Giovanoni 1991). The amplified polymerase chain reaction (PCR) product thus obtained was gel purified, quantified, and sequenced using an ABI PRISM 3100 Genetic Analyzer (Applied Biosystem). Sequence data obtained were analyzed, and consensus sequence was generated from forward and reverse sequences using "Aligner" software. These sequences were subjected to Basic Local Alignment Search Tool (BLAST) with National Center for Biotechnology Information (NCBI) GenBank database (Altschul et al. 1997). Based on maximum identity scores, the first ten identities were considered and the cultures were identified.

\section{Results and discussion}

Culture identification

Sequencing of the $16 \mathrm{~S}$ ribosomal RNA gene and analyzing the generated sequences using BLAST revealed that the isolate belonged to the genus Enterobacter. Hundred percent of homology to previously deposited sequences of Enterobacter strains was observed. The phylogenetic tree is presented in Fig. 1. The sequence has also been submitted to NCBI GenBank and has been allotted Accession Number KF420155.

PHA accumulation was verified using Nile blue staining technique, and the presence of orange fluorescence when
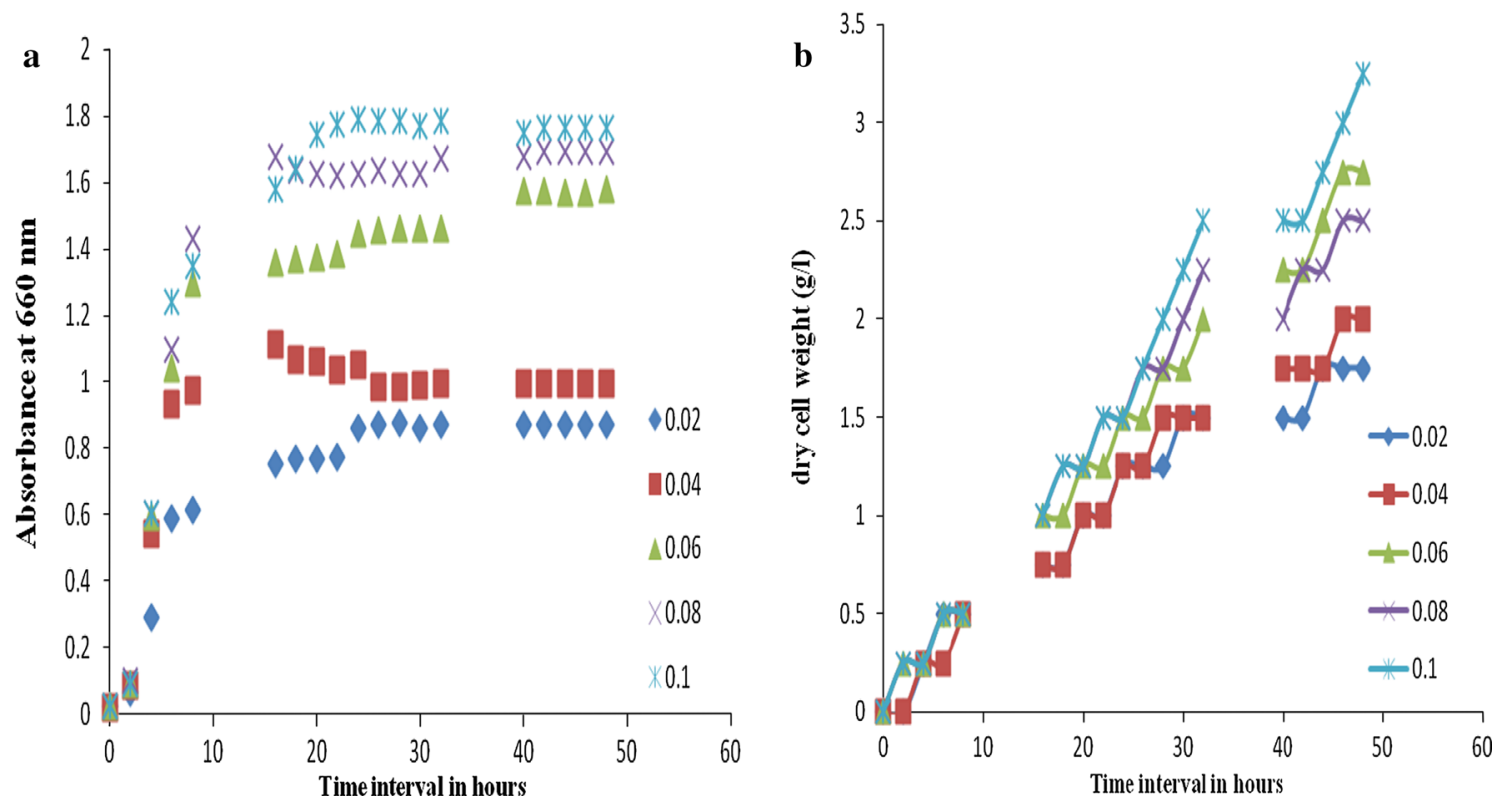

Fig. 2 a and b Biomass and dry cell weight obtained at various time intervals with different N/C ratios 

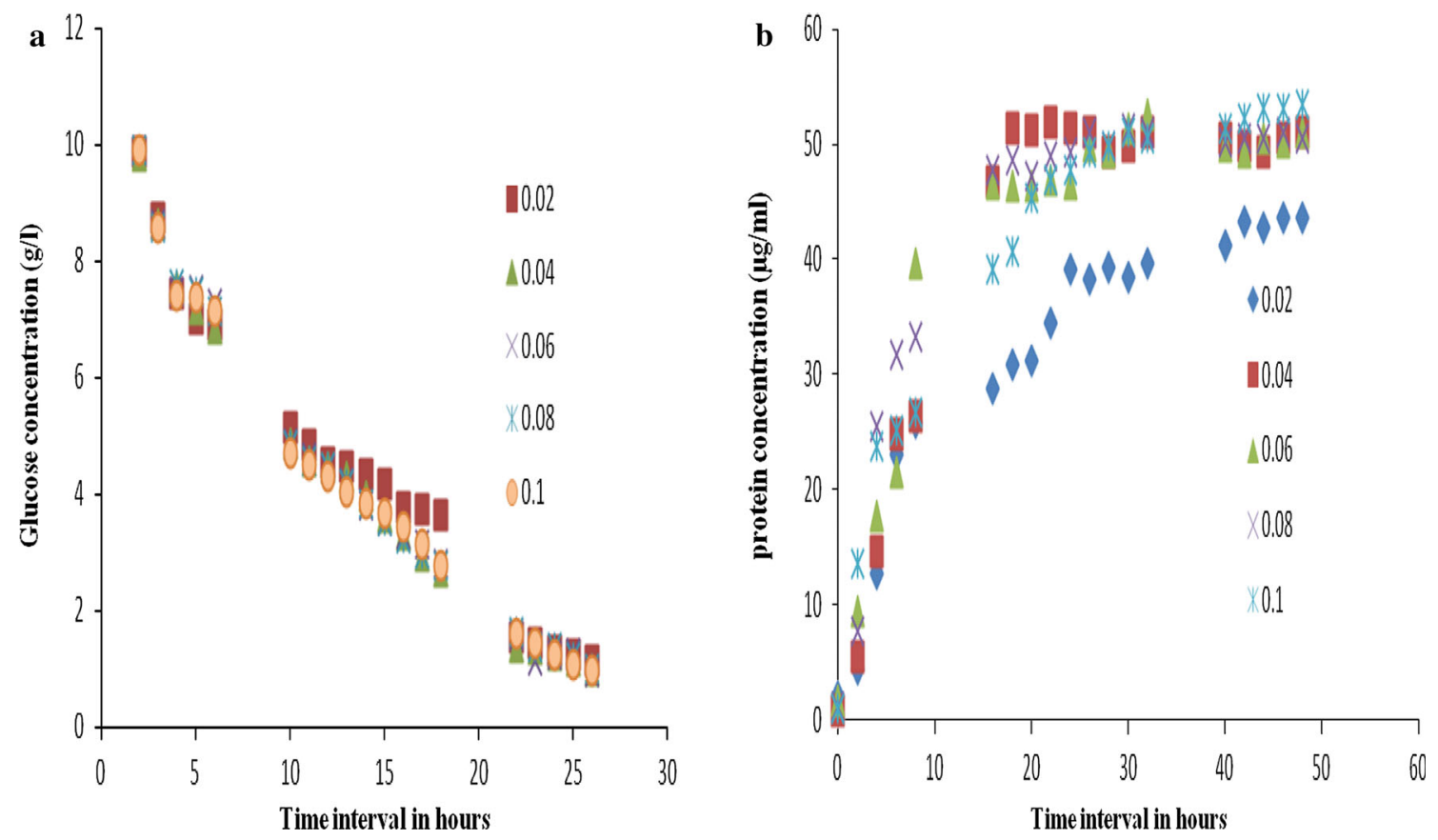

Fig. $3 \mathbf{a}$ and $\mathbf{b}$ Glucose concentration and protein concentration in the culture medium at various time intervals for different N/C ratios

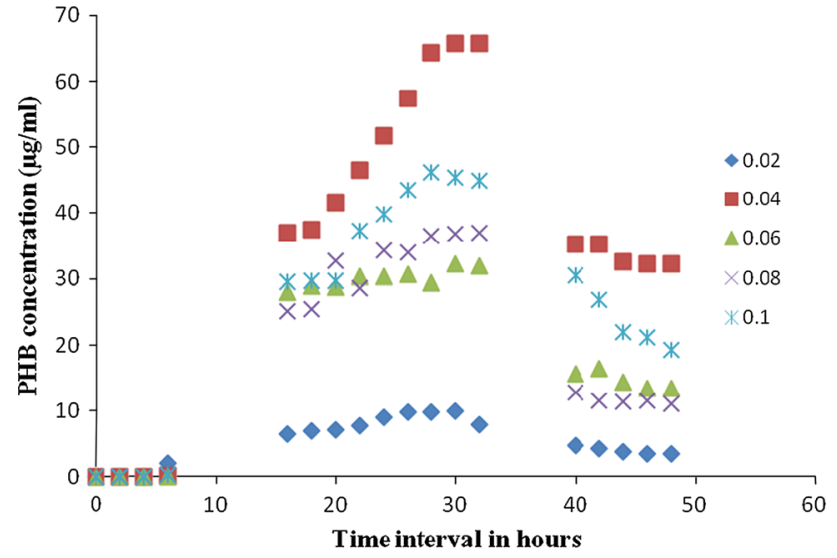

Fig. 4 PHA concentration at various time intervals for different N/C ratios

viewed under UV transilluminator at $460 \mathrm{~nm}$ confirmed the presence of PHA (Ostle and Holt 1982).

Biomass concentration and dry cell weight

The biomass concentration and dry cell weight obtained are shown in Fig. 2a, b, respectively. The maximum amount of biomass and dry cell weight of $3.25 \mathrm{~g} / \mathrm{l}$ was observed with $\mathrm{N} / \mathrm{C}$ ratio of 0.1 . PHA is produced by bacteria under nutrient-limiting conditions, especially when there is nitrogen-limiting stress, where the excessive carbon is converted to PHA (Sandhya et al. 2013). Understanding the optimum N/C ratio may help bringing down the substrate cost, thereby minimizing the medium wastage.
Glucose and protein concentration

Figure $3 \mathrm{a}, \mathrm{b}$ represents the residual glucose and protein concentrations in the culture broth, after growth of Enterobacter sp., for different N/C ratios. It was found that glucose concentration decreased with increase in biomass concentration and the protein content was also found to increase with respect to corresponding increase in biomass. PHA-producing bacterial species is known to consume and store excessive carbon source as an energy reserve in the form of PHA under nutrient-limiting conditions (Reddy and Mohan 2012).

\section{Quantification of PHA}

From the kinetic profile data (Fig. 4), it was found that maximum amount of PHA was accumulated at $28 \mathrm{~h}$ at N/C ratio of 0.04 . The glucose was utilized by Enterobacter for biomass production rather than PHA accumulation as stated by Raje and Srivasta (1998). In the earlier work reported (Sandhya et al. 2013) using Ralstonia eutropha MTCC1472 as a reference stain, maximal PHA production was obtained at $36 \mathrm{~h}$.

\section{Chemical characterization of PHA}

Chemical characterization and structure determination of PHA were carried out by two analytical techniques: FTIR and NMR. 
Fig. 5 a FTIR spectrum obtained for standard PHA. b FTIR spectrum of PHA obtained from Enterobacter sp.
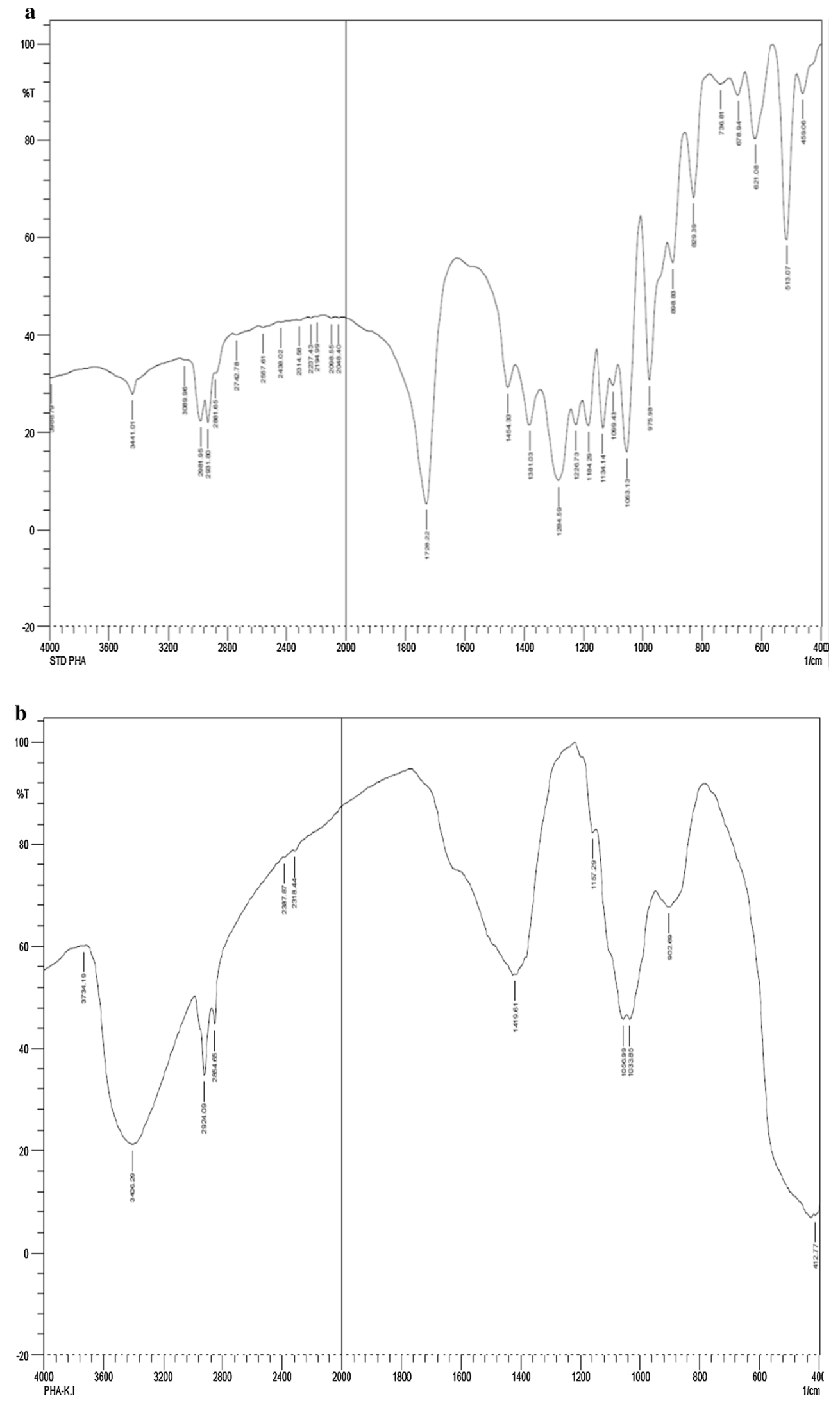
Fig. 6 a $\mathrm{H}^{1}$ spectra of standard PHA. b $\mathrm{H}^{1}$ spectra of PHA

obtained from Enterobacter sp. a

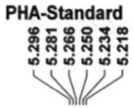

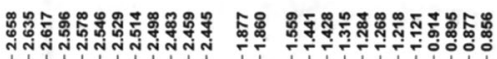

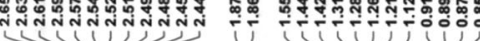

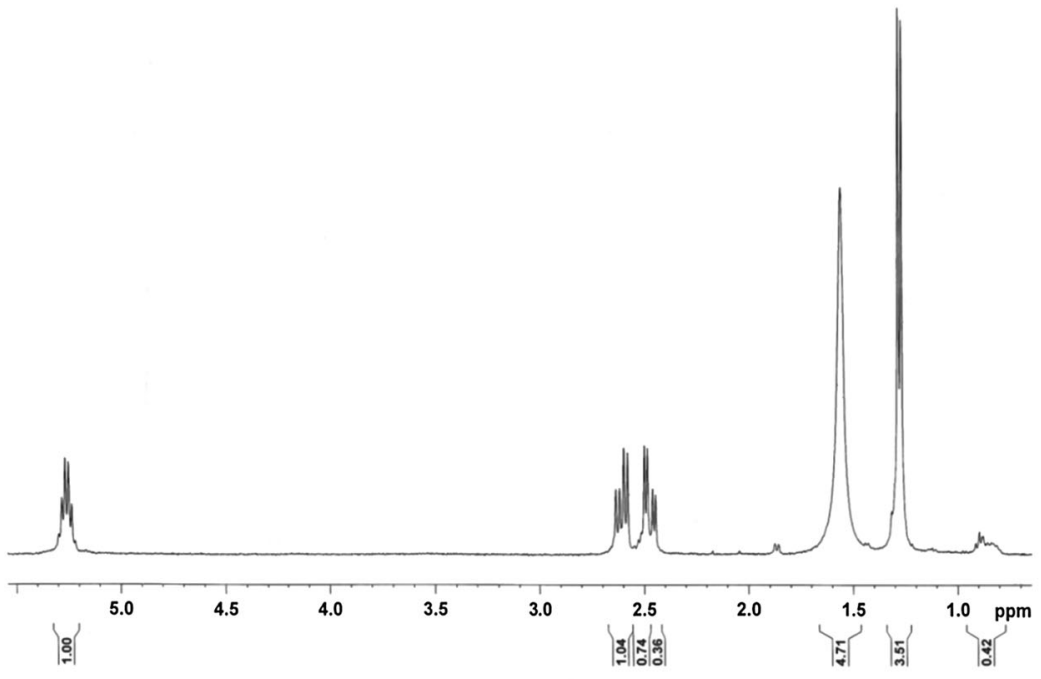

b

PHA-KI

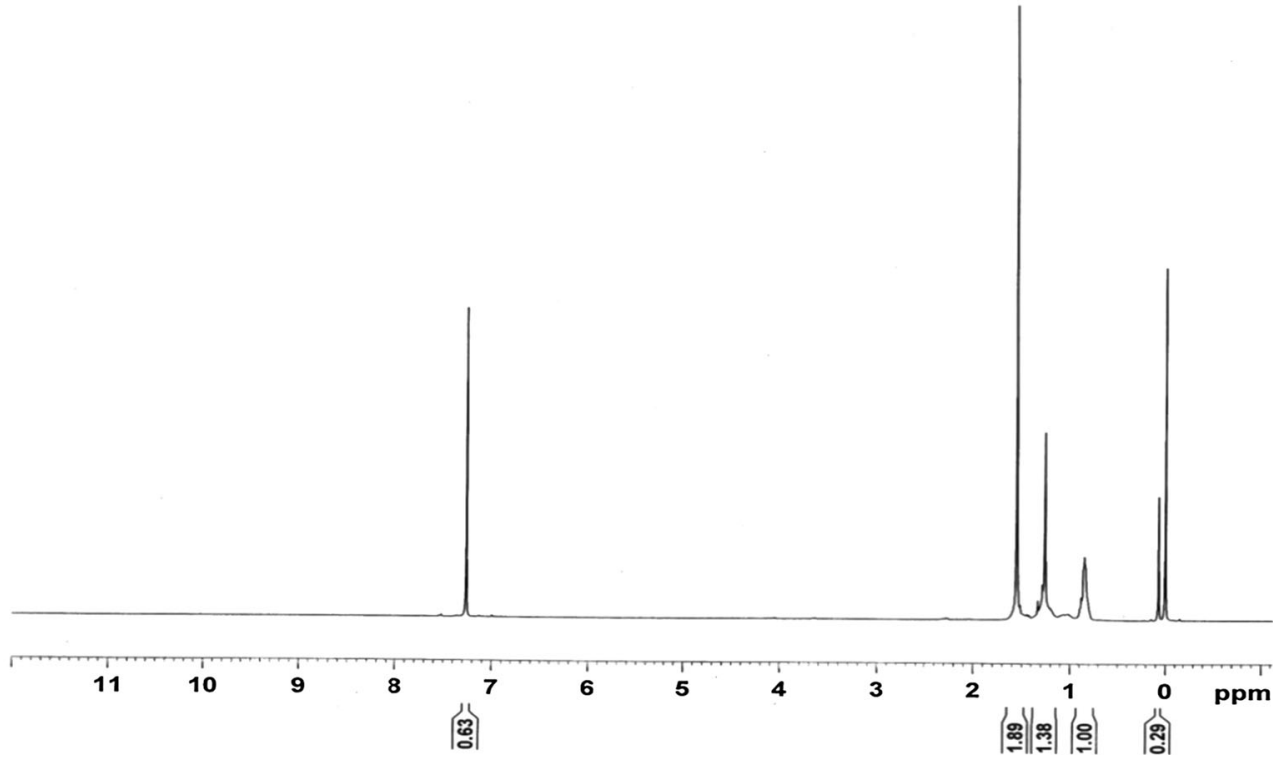

\section{FTIR analysis}

An FTIR spectrum was recorded in the range from 400 to $4000 \mathrm{~cm}^{-1}$. Figure 5a shows the spectrum of standard PHA molecule with a strong signal at $1728 \mathrm{~cm}^{-1}$ representing the characteristic peak of PHA. The intense bands at $2980-2850 \mathrm{~cm}^{-1}$ correspond to the aliphatic $\mathrm{C}-\mathrm{H}$ group; medium signals at $1000-1500 \mathrm{~cm}^{-1}$ represent the bending due to $\mathrm{CH}_{2}$ and $\mathrm{CH}_{3}$ and $1280-1050 \mathrm{~cm}^{-1}$ represent the bending due to valence symmetric and asymmetric stretch vibration of $\mathrm{C}-\mathrm{O}-\mathrm{C}$.

FTIR spectra of PHA extracted from Enterobacter sp. is shown in Fig. 5b. The absorption bands at $3600-3100 \mathrm{~cm}^{-1}$ represent the $\mathrm{OH}$ stretch and aliphatic $\mathrm{C}-\mathrm{H}$ group at 2954 and $2854 \mathrm{~cm}^{-1}$ (Sanchez et al. 2003), similar to standard PHA. The presence of weak symmetric 
Table 1 Characteristic peaks and the respective chemical groups of NMR spectra

\begin{tabular}{lll}
\hline ppm & Chemical compound & Reference \\
\hline 1.29 & $\mathrm{CH}_{3}$ resonance of PHB & Reddy and Mohan (2012) \\
1.57 & $\begin{array}{l}\text { Methylene protons next to methine } \\
\text { in side and main chain }\end{array}$ & Sato et al. (2012) \\
2.54 & $\begin{array}{l}\mathrm{CH}_{2} \text { of } \mathrm{C}_{2} \text { carbon (doublet in } \\
\text { figure) }\end{array}$ & Reddy and Mohan (2012) \\
\hline
\end{tabular}

peaks near $1447-1380 \mathrm{~cm}^{-1}$ suggests the presence of carboxyl group $(\mathrm{C}=\mathrm{O})$ in the polymer representing alkanoic acids in the sample (Nogabi et al. 2007). Intense peaks at $1500-1000 \mathrm{~cm}^{-1}$ represent the alkene and alkane bendings of $\mathrm{C}-\mathrm{O}$ stretch.

\section{NMR analysis}

Nuclear magnetic resonance spectrum was obtained for $\mathrm{H}^{1}$ proton at $400 \mathrm{MHz}$ by dissolving in deuterated chloroform. The obtained spectrum was compared to the standard PHA for structure determination.

Figure $6 a, b$ represents the spectrum obtained for standard and sample PHA polymer (Table 1). The sample spectra showed characteristic peak of PHA at $1.2 \mathrm{ppm}$ and peaks similar to standard PHA (Wang and Liu 2014).

\section{Conclusion}

An optimization of the nutrient feeding strategy for higher PHA accumulation in the novel strain of Enterobacter sp was attempted. Nutrient feeding strategy under favorable N/C ratio positively impacted PHA accumulation and biomass quality. Higher PHA accumulation was found at $\mathrm{N} / \mathrm{C}$ ratio of 0.04 at $28 \mathrm{~h}$. This study emphasizes the role of nitrogen under nutrient-limiting condition, impacting PHA biopolymer accumulation and biomass production. Understanding the optimum N/C ratio can enhance the efficiency of overall PHA production with added advantage of minimizing the nutrient wastage.

Acknowledgments The authors would like to thank the management of Kumaraguru College of Technology for the research facilities provided and Mr. M. Shanmugaprakash and Dr. Vinohar Stephen Rapheal for their invaluable help during the work.

\section{References}

Albuquerque MGE, Eiroa M, Torres C, Nunes BR, Reis MAM (2007) Strategies for development of side stream process for polyhydroxyalkanoate (PHA) production from sugarcane molasses. J Biotechnol 130:411-421

Altschul SF, Madden TL, Schaffer AA, Zhang J, Zhang Z, Miller W, Lipman DJ (1997) Gapped BLAST and PSI-BLAST: a new generation of protein database search programs. Nucleic Acids Res 25:3389-3402

Anderson AJ, Dawes EA (1990) Occurrence, metabolism, metabolic rate, and industrial uses of bacterial polyhydroxyalkonate. Microbiol Rev 54:450-472

Dalal J, Sarma MP, Lavania M, Mandal KA, Lal B (2010) Evaluation of bacterial strains isolated from oil-contaminated soil for production of polyhydroxyalkanoic acids (PHA). Pedobiologia $54: 25-30$

Giovanoni SJ (1991) The polymerase chain reaction. In: Stackebrandt E, Goodfellow M (eds) Nucleic acid techniques in bacterial systematics. Wiley, New York, pp 177-203

Heimersson S, Morgan-Sagastume F, Peters GM, Svanstrom M (2014) Methodological issues in life cycle assessment of mixedculture polyhydroxyalkanoate production utilising waste as feedstock. New Biotechnol 331(4):383-393

Law J, Slepecky RA (1969) Assay of poly-hydroxybutyric acid. J Bacteriol 82:52-55

Laycock B, Halley P, Pratt S, Werker A, Lant P (2014) The chemomechanical properties of microbial polyhydroxyalkanoates. Prog Polym Sci 39(2):397-442

Nogabi AK, Zahiri SH, Yoo SC (2007) The production of cold induced extracellular polymer by Pseudomonas fluorescens BM07 under various growth conditions and its role in heavy metals absorption. Process Biochem 42:847-855

Ojumu TV, Yu J, Solomon BO (2004) Production of polyhydroxyalkonate, a bacterial biodegradable polymer. Afr J Biotechnol 43:8-24

Ostle AG, Holt JG (1982) Nile Blue A as a Fluorescent Stain for Poly3- Hydroxybutyrate. Appl Environ Microbiol 44:238-241

Philip S, Keshavarz T, Roy I (2007) Polyhydroxyalkanoates: biodegradable polymers with a range of applications. J Chem Technol Biotechnol 82(3):233-247

Poirier Y, Dennis DE, Klomparens K, Somerville C (1995) Polyhydroxybutyrate, a biodegradable thermoplastic produced in transgenic plants. Science 256:520-523

Raje P, Srivasta AK (1998) Updated mathematical model and fed batch strategies for poly- $\beta$-hydroxybutyurate $(\mathrm{PHB})$ production by Alcaligenes eutropus. Bioresour Technol 64:185-192

Reddy VM, Mohan VS, (2012) Effect of substrate load and nutrient concentration on the polyhydroxyalkanoates (PHA) production using mixed consortia through waste water treatment. Bioresour Technol 114:573-582

Reddy MM, Vivekanandhan S, Mishra M, Bhatia SK, Mohanty AK (2013) Biobased plastics and bionanocomposites: current status and future opportunities. Prog Polym Sci 38:1653-1689

Sanchez R, Schripsema J, Silva FL, Taciro KM, Pradella GCJ, Gomez G (2003) Medium chain length polyhydroxy alkonoic acids produced by $P$. putita IPT 046 from renewable resource. Eur Polym J 39:1385-1394

Sandhya M, Aravind J, Kanmani P (2013) Production of polyhydroxyalkanoates from Ralstonia eutropha using paddy straw as cheap substrate. Int J Environ Sci Technol 10(1):47-54

Sato S, Ishii N, Hamada Y, Abe H, Tsuge T (2012) Utilization of 2-alkenoic acids for biosynthesis of medium-chain-length polyhydroxyalkanoates in metabolically engineered Escherichia coli to construct a novel chemical recycling system. Polym Degrad Stabil 97(3):329-336 
Scholz C, Gross RA (2000) Poly ( $\beta$-hydroxyalkanoates) as potential biochemical material polymers: an overview from renewable resources-biopolymers and biocatalysis. ACS Ser 764:328-334

Thompson CR, Moore C, Saal FS, Swan HS (2009) Plastics, the environment and human health: current consensus and future trends. Phil Trans R Lond B Biol Sci 364:2153-2166
Wang Y, Liu S (2014) Production of (R)-3-hydroxybutyric acid by Burkholderia cepacia from wood extract hydrolysates. AMB Expr 4:28

Yuksekdag ZN, Beyatu Y, Aslim B (2003) Determination of poly- $\beta$ hydroxybutyrate $(\mathrm{PHB})$ production by some mesophilic and thermophilic lactic acid bacteria. Turk J Biol 27:37-42 